\section{Nociones de justicia, legalidad y legitimidad de las normas entre jóvenes de cinco países de América Latina*}

Recebido: 07.01.15

Aprovado: 18.02 .15

\author{
Arturo Alvarado Mendoza**
}

Resumo: Vários países da América Latina têm se engajado em uma guerra extremamente violenta contra as drogas, as gangues e o crime organizado. Os governos e as elites latino-americanas têm implementado uma série de reformas institucionais, questionáveis tanto no âmbito da justiça quanto no dos sistemas jurídicos, com a intenção, fracassada, de fazer frente a esta guerra. Sua implementação tem sido corroída pela incapacidade das mesmas elites de respeitar estas regras, porque existe uma forte corrupção e a cultura da impunidade. Este comportamento tem forte impacto nas expectativas dos cidadãos, em sua percepção de impunidade, de corrupção e dos valores da democracia e do Estado de direito. Em meio a estas batalhas, a população jovem tem sido alvo e considerada culpada em relação a crimes de grande gravidade os quais, na verdade, foram perpetrados pelos diferentes atores legais, armados. Uma questão é a crescente participação que os jovens assumiram nessas atividades ilegais. Outra questão é a das crianças, sua socialização nas normas jurídicas, seu consentimento e reconhecimento.

Palavras-chave: jovens, percepção, justiça, leis, polícia.

\section{Introducción}

E ste artículo presenta una exploración inicial comparativa de las percepciones que tienen los jóvenes de cinco países de América Latina sobre las normas legales, sobre su conocimiento, aceptación, legitimidad de las normas y de las instituciones asociadas a ellas, en particular las normas penales y las autoridades policiales. El trabajo presenta evidencias de un estudio de jóvenes habitantes de barrios populares en 10 ciudades Latinoamericanas. La información fue recabada en entrevistas individuales, colectivas y en un conjunto de grupos focales en el año 2012.

El trabajo también propone abordar críticamente los estudios sociológicos sobre la socialización, la internalización y el uso de las normas legales, particularmente aquellos enfoques que establecen proposiciones generales sobre la legitimidad de un orden, el cinismo frente a éste o la desafiliación. Nuestro estudio explora qué conocen los jóvenes de esas normas, de sus derechos y cómo responden ante situaciones hipotéticas de uso de las normas.

Gran parte de los jóvenes en el estudio aceptan las normas legales impuestas por las elites políticas (sin conocer ni entender cómo se construyen) y tienden a prac-

\author{
* Agradezco a \\ Alejandro Ocaña, \\ Susana Esquivel \\ y Úrsula Alanís su \\ colaboración para \\ armar este trabajo. \\ Revisão do espanhol \\ realizada por Analía \\ Laura Soria Batista. \\ ** El Colegio de \\ México, \\ profesor investigador, \\ Centro de Estudios \\ Sociológicos. \\ <E-mail: alvarado@ \\ colmex.mx>.
}


ticarlas, aceptarlas, rechazarlas o romperlas en sentidos contextuales, prácticos y casuísticos. En este relativismo difieren del propósito universalista y formalista de su aplicabilidad. Pero también el trabajo muestra que la mayoría de los jóvenes tienen un escaso conocimiento de sus derechos, pero tienden a conocer en términos generales las normas legales (sobre todo ciertas normas penales) y presentan cierto consenso respecto de los principios que sustentan estas normas; en lo que respecta al ejercicio cotidiano de ellas, por las razones que expondremos adelante. Por otro lado, el trabajo muestra cierta vinculación entre algunas convenciones sociales, otras concepciones morales y religiosas de lo que es correcto y lo que es el bien (individual o colectivo), que no necesariamente están en correspondencia con lo que las normas definen, proponen y sancionan.

Expondremos las respuestas a una serie de ejercicios y mostraremos en qué sentido utilizan, obedecen o rompen con las normas en forma casuística, frente a un imaginario estado de derecho.

La mayoría tiende a aceptar y a comportarse de acuerdo con la norma, pero también tiende a criticar "desengancharse" de aquellas que considera injustas. Así, la obediencia a la ley parece estar asociada a una particular concepción de justicia y legitimidad de las normas, lo que nos obliga a revisar críticamente la literatura al respecto. Las entrevistas revelan que los jóvenes distinguen y comentan cómo la élite ejerce la ley y lo que esta práctica tiene como propósito genérico. La visión de cómo se comportan las autoridades, los poderosos y sus representantes, tales como la policía o los jueces, es muy importante en la valoración, la aceptación y la obediencia a la norma. Critican el ejercicio arbitrario de las leyes. Además, el estudio indica que en ciudades con altos niveles de violencia, criminalidad y de impunidad, el contexto determina una visión diferente del ejercicio y la aplicación de la norma, más allá de su valor formal. En este sentido, es necesario explorar: cómo los jóvenes conciben y practican sus nociones de justicia y ley; cómo las definen y en qué casos y contextos las aplican; y cuándo y en qué situaciones las consideran legales, legítimas, justas.

Los jóvenes de barrios populares entrevistados conocen generalmente las normas y las reglas penales, gran parte de ellos las considera limitadas, injustas y discriminatorias, sobre todo aquellas que les afectan y que les son aplicadas por las autoridades (especialmente la policía). La aplicación de la norma genera controversias sostenidas. Sin embargo, tienden a reconocer que algunas bases de las leyes son justas y legítimas (con excepción de aquellas que los discriminan) porque tienden a aceptar el marco general, genérico y abstracto, de una justicia ideal, justa e igualitaria. Tienden a rechazar la aplicación por los gobernantes, lo cual indica que entienden y distinguen entre la norma abstracta y la aplicación concreta de la ley. Ellos se socializan en un ambiente diferente y conflictivo frente a las élites. 
A continuación haremos una revisión de la literatura sobre el tema, para enmarcar el análisis y la clasificación que realizamos de los ejercicios realizados por los jóvenes.

\section{Socialización legal}

Una línea de estudios vinculados con la "justicia procedimental" es complementaria con el análisis de la socialización legal en niños y adolescentes ${ }^{1}$. Ésta toma como antecedentes una serie de estudios de influencia piagetiana, sobre la conformación de los juicios morales en los niños y adolescentes (Tapp \& Levine, 1977; Hyman, 1959). Desde un interés en conformar una "buena sociedad", la idea es que las primeras experiencias con instituciones y actores ligados con la ley, irán configurando las percepciones y las actitudes posteriores, así como una mayor disponibilidad de colaboración con las instituciones legales siendo la policía una de las principales autoridades. En contraparte, malas experiencias tempranas disminuirán esa conformidad y la disponibilidad a colaborar con la ley. No se trata sólo de la experiencia personal; también determinados contextos barriales y grupos de pares pueden afectar esa socialización en normas legales. Desde este punto de vista sería interesante diferenciar entre las consecuencias de estos contactos en jóvenes que ya han tenido conflictos con la ley (esto es, que han sido detenidos y procesados por la autoridad por cometer delitos) y otros que no los han tenido. Esto mostraría las dos caras del proceso de socialización.

En este proceso de socialización legal, un tema central es la legitimación de la ley y de las instituciones. Por su parte, la socialización legal comprende tres dimensiones: 1. legitimidad institucional, 2. cinismo acerca del sistema legal y 3. retraimiento moral. La primera se refiere al sentimiento de obligación deferido a las instituciones legales y a los actores. El grado en que la gente siente que debe obedecer las decisiones de las autoridades legales, aun cuando considera que son erradas o no son conformes con sus intereses. La gente tiene opiniones distintas sobre la legalidad de los actos de las autoridades. Pero también puede considerar que la ley es correcta. La pregunta central de las investigaciones es si la legitimidad es suficiente para que se acepten y se respeten determinadas leyes, ordenanzas u otro tipo de normas, más allá del propio acuerdo o coincidencia de intereses de cada uno.

Tyler (2001) se refiere a una sociedad en la cual hay una conformidad internamente motivada hacia la ley y las autoridades legales como una "sociedad respetuosa de la ley" (law abiding society) diferente a las sociedades latinoamericanas. Este tipo de sociedades, formalmente no requeriría muchos esfuerzos adicionales para lograr el control social del delito ya que la necesidad de regulación por mecanismos de disuasión puede ser minimizada (pero los acontecimientos recientes en Europa en enero de 2015 indican que esta idea requiere revisarse). Distintos autores han hecho hin-
1. Esta sección es parte de un trabajo realizado junto con José Alfredo Zavaleta, Gabriel Kessler, Jorge Zaverucha y el autor, sobre las interacciones entre la policía y los jóvenes en América Latina, en prensa. En este sentido varias de las ideas y de los ejemplos de socialización tienen que ver con las prácticas policiales. 
2. El valor de la llamada legitimidad situacional es demostrado por investigaciones que muestran que cuando la legitimidad de la intervención es baja, la policía tiene mayor probabilidad de usar la fuerza física, generándose también mayores riesgos de lesiones para el arrestado y para la policía (Reiss, 1972). capié en los beneficios de una sociedad que está internamente regulada, minimizando de este modo la necesidad de vigilancia y control (Tyler \& Huo 2002; Hirschi, 1969). De este modo, nos interesa encontrar las claves de esta autorregulación.

Un tema central aquí son las formas de construcción de legitimidad de las agencias públicas, porque es una de las claves de la cooperación entre ellas. Enmarcado en los trabajos de autoridad legítima weberiana, estos trabajos se interesan en la forma en que en el interior de las comunidades surge una legitimidad por las prácticas y acciones que ejerce la autoridad, que formalmente tiene la ventaja de ser voluntaria y que no depende de una evaluación constante del buen desempeño policial. Así, una autoridad legítima es una autoridad considerada por la gente como con derecho a que sus reglas y decisiones sean aceptadas y seguidas por los otros. Habría que discutir si es posible diferenciar la legitimidad general, ligada a la institución, de la legitimidad particular, que sustentan agentes en acciones legales concretas. Esta visión es particularmente relevante en muchos de nuestros países, donde en general la mirada sobre la policía es muy negativa, en tanto institución, aun cuando puede haber, por el contrario, mayor legitimidad de agentes particulares con los cuales se tiene trato cotidiano ${ }^{2}$.

En otra orientación, el cinismo legal es otro enfoque sobre la legitimidad de la ley y de las normas sociales. Su base son los estudios sobre anomia, pero con el tiempo se han vinculado más bien a los estudios de subculturas urbanas y las formas en que expresan una relación distinta con la ley. En tal sentido, se nota un alejamiento de la ley con respecto de las necesidades del grupo cuando individuos o grupos consideran "razonable" actuar fuera de la ley. Dentro de estos trabajos tenemos "técnicas de neutralización" de Sykes y Matza (2008) que dan cuenta de técnicas argumentativas para justificar (o al menos para minimizar la responsabilidad) la violación de la ley (minimización de la culpa, inversión de la responsabilidad, negación del daño, etc.).

Un enfoque que ha trabajado sistemáticamente la forma como las personas definen su orientación y obediencia hacia la norma ha sido definido como cinismo legal (definido en el diccionario de inglés Webster's como una persona que cree que su acciones están motivadas solamente por su propio interés personal (egoísta) y no actúa con base en razones honorables de reciprocidad o altruistas (Simon and Shuster International Dictionary). Las personas cínicas legalmente hablando, son aquellas que tienden a desafiliarse de las leyes, actuar y determinar su conducta en función de su interés personal, aun cuando éste vaya contra la norma. También nos referimos a aquellas personas que actúan en contra de valores de honestidad, confianza integridad (respecto al comportamiento ante la ley). Esto también refleja la consistencia de sus comportamientos frente a las normas. Ulteriormente, Sampson y Bartusch (1998) han definido este concepto como cinismo legal. 
Por último, otro enfoque sería el que enfatiza el tema de comportamiento como desafiliación a las normas, las leyes o los estándares sociales. Esto lo traducimos como "retraimiento moral" (moral disengagement) y comprende la separación de una conducta de los parámetros morales relevantes (Bandura, 1990). Presupone que la conducta adolescente es configurada con arreglo a valores morales y que la conducta ilegal es inconsistente con los valores morales. En la medida en que una persona separa conductas de los valores morales que le darían freno, mayor es la tendencia a emprender acciones, en particular delitos, inconsistentes con dichos parámetros.

A medida que se pasa de la niñez a la adolescencia, aumenta el cinismo legal, disminuye la legitimidad y aumenta el retraimiento moral (Fagan y Tyler, 2004). El cinismo legal y la legitimidad estarán influidos claramente por la justicia de procedimiento, en el sentido que experimentar personalmente injusticias de procedimiento incrementa el cinismo y disminuye la legitimidad institucional. Por su parte, el retraimiento moral estará más influido por el grupo de amigos y por contextos barriales muy violentos, de crimen alto.

Nuestros hallazgos tratan de mostrar los factores influyentes en la construcción de cada una de estas dimensiones de la "socialización legal". Lo que es interesante de estos textos es que muestran que en la niñez y en la primera adolescencia, la conformidad con la ley y la legitimidad de las autoridades es alta. En gran medida, los tipos de relaciones que niños y adolescentes establecen con la autoridad van limitando o minando su legitimidad y, por ende, la conformidad con la ley y cualquier idea de colaboración con ella. Si la percepción de justicia de procedimiento es mala, la percepción de la ley será muy baja, siendo una clave de lectura importante en nuestro contexto en los esfuerzos por explicar el delito juvenil.

Pero, además de estos enfoques fundamentalmente desarrollados por la literatura anglosajona ¿qué ocurre cuando las personas perciben que existe un doble estándar? Por ejemplo: que las autoridades que definen las reglas, también deciden cuándo y cómo aplicar la ley de acuerdo con su propio interés, y que este interés difiere del resto de la población porque permite que los poderosos quebranten la ley y los desposeídos son castigados.

Los jóvenes perciben que hay "incertidumbre jurídica" en la forma en que la ley es aplicada. La forma como las autoridades aplican la ley no está en correspondencia directa con la norma general, y las sanciones que aplican (su severidad o benevolencia) tampoco están en correspondencia con la importancia (gravedad) de la falta, sobre todo cuando un político o un joven rompen una regla. Muchos jóvenes rechazan esta aplicación discrecional de la norma, otros más, como lo mostraremos, 
3. Los co-autores son: México: Ciudad de México: Arturo Alvarado Mendoza y Gabriela Figueroa López; Ciudad Juárez, Chihuahua: Angélica Durán y Úrsula Alanís; León, Gto.: Jesica Vega; Cancún, Q. R.: Araceli Nava; Xalapa, Veracruz: José Alfredo Zavaleta. Argentina: Buenos Aires: Gabriel Kessler y Sabina Dimarco. Colombia: Santiago de Cali: Alberto ConchaEastman y Natalia Concha; Medellín: Angélica Durán. Brasil: São Paulo, Maria Fernanda Tourinho Peres, Maria de Lourdes Trassi Teixeira, Marina Decot Sdoia y Roberta Tinoco. Guatemala: Ulises Urusquieta. Proyecto financiado por el International Development Research Centre, de Cánadá, número 106289. extraen consecuencias o razonamientos generales de estos actos. Esto no significa, sin embargo, que su comportamiento sea cínico. Más bien hay una visión casuística-pragmática de la norma. Porque ellos ven que la legalidad y la justicia están sujetas a una aplicación arbitraria del poder (de la elite).

En una forma paralela a la literatura, propondremos una interpretación diferente respecto del proceso de socialización de las normas y su reconocimiento entre los grupos de jóvenes del estudio. Asimismo, en la medida en que el material nos lo permita, mostraremos las consecuencias que este comportamiento particular (no sólo individual) tiene para los jóvenes, para el ejercicio del sistema legal y para las autoridades. Veamos algunos trabajos al respecto, para luego exponer los resultados de un ejercicio aplicado a una muestra de jóvenes de barrios precarios en el subcontinente.

\section{Base de datos del artículo y procedimiento de aplicación del ejercicio}

Los datos de este trabajo provienen de un proyecto comparativo internacional sobre violencia juvenil en América Latina coordinado por el autor ${ }^{3}$. El ejercicio fue realizado con grupos focales en barrios populares de diez ciudades de América Latina, Buenos Aires, Argentina., Cali y Medellín, Colombia, São Paulo, Brasil., Guatemala en Guatemala y en México: Cancún, Ciudad Juárez, Ciudad de México, León y Jalapa

TABLA 1

RELACIÓN DE ENTREVISTAS Y GRUPOS FOCALES DEL PROYECTO VIOLENCIA JUVENIL Y ACCESO A LA JUSTICIA EN AMÉRICA LATINA

\begin{tabular}{|c|c|c|c|c|}
\hline $\begin{array}{c}\text { Buenos Aires, } \\
\text { Argentina }\end{array}$ & $\begin{array}{c}\text { Cali, } \\
\text { Colombia }\end{array}$ & $\begin{array}{l}\text { Medellín, } \\
\text { Colombia }\end{array}$ & $\begin{array}{c}\text { São Paulo, } \\
\text { Brasil }\end{array}$ & Guatemala \\
\hline $\begin{array}{l}2 \text { grupos focales } \\
\text { mixtos, el primero } \\
\text { con jóvenes de } 14 \text { a } \\
18 \text { años y el segundo } \\
\text { con jóvenes de } 19 \text { a } \\
25 \text { años. }\end{array}$ & $\begin{array}{l}10 \text { entrevistas } \\
\text { autoridades estatales, } \\
4 \text { entrevistas con } \\
\text { especialistas, } 6 \\
\text { entrevistas con ONG's } \\
\text { y cuatro Grupos } \\
\text { Focales }\end{array}$ & $\begin{array}{l}7 \text { entrevistas ONG's, } \\
8 \text { entrevistas con } \\
\text { autoridades estatales, } \\
2 \text { entrevistas con } \\
\text { especialistas y } 3 \\
\text { entrevistas colectivas } \\
\text { con jóvenes. }\end{array}$ & $\begin{array}{l}4 \text { grupos Focales, 1-- } \\
\text { Jóvenes de } 19 \text { a } 27 \\
\text { años de edad (mixto). } \\
\text { 20-- Jóvenes de } 14 \\
\text { a } 17 \text { años (mixto), } \\
\text { 3o-Jóvenes de } 15 \text { a } 18 \\
\text { años y } 4 \text {-- Jóvenes de } \\
15 \text { a } 18 \text { años. }\end{array}$ & $\begin{array}{l}20 \text { entrevistas indivi- } \\
\text { duales a jóvenes, } 10 \\
\text { entrevistas a policías. }\end{array}$ \\
\hline $\begin{array}{c}\text { Ciudad } \\
\text { de México }\end{array}$ & $\begin{array}{c}\text { Cancún, } \\
\text { Quintana Roo }\end{array}$ & $\begin{array}{l}\text { Cd. Juárez, } \\
\text { Chihuahua }\end{array}$ & $\begin{array}{l}\text { León, } \\
\text { Guanajuato }\end{array}$ & $\begin{array}{l}\text { Xalapa, } \\
\text { Veracruz }\end{array}$ \\
\hline $\begin{array}{l}38 \text { entrevistas indi- } \\
\text { viduales, } 5 \text { Grupos } \\
\text { Focales con jóvenes, } \\
1 \text { entrevista grupal } \\
\text { con policías. }\end{array}$ & $\begin{array}{l}4 \text { Grupos focales, } 2 \\
\text { con adolescentes con } \\
\text { algún conflicto con la } \\
\text { ley mixto y } 2 \text { con ado- } \\
\text { lescentes sin conflicto } \\
\text { con la ley. }\end{array}$ & $\begin{array}{l}7 \text { grupos focales, } \\
2 \text { entrevistas con } \\
\text { autoridades estatales, } \\
2 \text { entrevistas con } \\
\text { especialistas. }\end{array}$ & $\begin{array}{l}18 \text { entrevistas indi- } \\
\text { viduales con jóvenes } \\
\text { y autoridades, } 3 \\
\text { grupos focales, } 2 \\
\text { entrevistas colectivas } \\
\text { con policías. }\end{array}$ & $\begin{array}{l}2 \text { grupos focales, uno } \\
\text { con jóvenes de } 14 \text { a } \\
18 \text { años y el otro con } \\
\text { jóvenes de } 18 \text { a } 24 \\
\text { años. }\end{array}$ \\
\hline
\end{tabular}

Fuente: Elaboración del autor con base en el libro Violencia Juvenil en América Latina. El Colegio de México, 2014. 
(ver cuadro). Los jóvenes de este trabajo fueron reclutados por los colegas co-participes del estudio y en cada ciudad fueron seleccionados al menos tres grupos de mujeres y hombres jóvenes entre 16 y 24 años de edad, además, con un grupo que enfrenta conflictos con la ley.

Para obtener información sobre el conocimiento y aceptación de las normas diseñamos un ejercicio de clasificación de conceptos y palabras, en donde solicitamos a los asistentes clasificar un conjunto de términos en tres diferentes formas, anunciados en tarjetas, para generar una discusión entre ellos (ver lista), varias palabras refieren a normas legales mientras que otras son normas o convenciones sociales.

TABLA 2

LISTA DE PALABRAS CLAVE QUE

SE UTILIZARON EN LOS GRUPOS DE ENFOQUE

\begin{tabular}{|c|c|c|c|}
\hline Gritar & Portar arma & Monearse & Violación \\
\hline Golpear & Drogarse & Extorsión & Prostitución \\
\hline Robar & Beber en vía pública & Mordida & Bandas armadas \\
\hline Aborto & Matar & Grafiti & Acoso \\
\hline Perreo & Piratería & Riña & Bajar el novi@ \\
\hline Chismes & Venta de drogas & Pandilla & Hostigamiento \\
\hline
\end{tabular}

La primera parte del ejercicio consistió en clasificar las palabras de acuerdo con su respuesta como aceptable, no aceptable o indiferencia, para encontrar convergencias y desacuerdos. Solicitamos al grupo que ellos buscaran consensos y disensos y argumentaran sobre estos.

\begin{tabular}{|l|l|l|l|}
\hline Aceptable & Me es indiferente & No aceptable & Desacuerdos \\
\hline
\end{tabular}

En la segunda parte del ejercicio clasificaron las palabras como me molesta, no me molesta o indiferencia y continuamos con el mismo procedimiento.

\begin{tabular}{|c|c|c|}
\hline "Me molesta" & "no me molesta" & "me es indiferente" \\
\hline
\end{tabular}

Y en la tercera ocasión les solicitamos que indicaran si las consideraban legales, ilegales o desconocer su clasificación (no lo sé).

\begin{tabular}{|l|l|l|}
\hline "Legal" & "Ilegal" & "No lo sé" \\
\hline
\end{tabular}


4. Las respuestas fueron muy diferentes y no fue posible aplicarlo en todos lados.

5. La lista aparece en la tabla 1.

6. Página 90.
Luego, clasificamos las respuestas y exploramos aquellas convergencias, las que producían divergencias, las que mostraban confusiones, conocimientos y opiniones divergentes. Para continuar la exploración les preguntamos cuáles de las conductas descritas por las palabras eran más frecuentes en sus comunidades y cuáles consideraban que podrían definirse como criminales. También preguntamos por qué pensaban ellos que había convergencias y divergencias. Las respuestas de uno de los casos serán presentadas más adelante.

Aplicamos el ejercicio en la mayoría de los 38 grupos focales y entrevistas colectivas en las 10 ciudades seleccionadas. (São Paulo, Brasil, Buenos Aires, Argentina, MedeIlín y Cali en Colombia, Guatemala, Guatemala, y Cancún, México D.F., León, Ciudad Juárez y Xalapa en México $)^{4}$. Antes de aplicarlo probamos un conjunto de términos relacionados con actividades cotidianas de los jóvenes que pueden asociarse a conductas y normas legales 5 . Después de aplicar el ejercicio llegamos a una clasificación base para todos los grupos (Alvarado, 2014).

La tabla (3) y la (figura 1$)^{6}$ muestran la distribución hipotética de las respuestas en torno a las ideas-ejes de aceptabilidad, justicia, legitimidad y legalidad. Estas implícitamente manifiestan el conocimiento y la aceptación de un orden de acuerdo con las prácticas cotidianas de los jóvenes. A lo largo de las entrevistas obtuvimos una importante variedad de respuestas a los temas preguntados, de forma que podemos construir un imaginario sobre la legalidad en sus discursos. Podríamos construir una escala con los tres temas que nos indicara el grado de reconocimiento y aceptación de las leyes. Así concluir algunas conjeturas respecto del proceso de socialización de estos jóvenes.

TABLA 3

DISTRIBUCIÓN HIPOTÉTICA IDEAL DE LAS RESPUESTAS

\begin{tabular}{|c|c|c|}
\hline Justo & Legal & Injusto \\
\hline Legítimo & $\begin{array}{c}\text { Ambivalencia, relativismo } \\
\text { Contradicciones, disonancias }\end{array}$ & Ilegítimo \\
\hline Aceptable & Ilegal & Inaceptable \\
\hline
\end{tabular}

Ejes: legal - ilegal; justo - injusto; aceptable - no aceptable; legítimo - ilegítimo.

Las respuestas propensas a un orden justo, legítimo y legal, estarían en el cuadrante superior izquierdo; las opuestas estarían en el inferior derecho y corresponderán a un orden cardinal que conoce y acepta las leyes, no obstante que algunos ejercicios personales puedan estar en contra de algunas de ellas. En el grupo de en medio estarán distribuidas todas aquellas posiciones ambivalentes, relativistas o casuísticas, cercanas al cinismo legal y, en los casos extremos, desafiliación cultural y legal. 
Cabe agregar aquí que es de esperarse alguna disonancia en las respuestas, esto es, situación en que conocen la ley pero no la aplican en forma lógica, sino contraria a lo esperado.

\section{Resultados}

Como resultado general hay que mencionar el escaso conocimiento de los derechos de que son titulares. En los ejercicios solicitamos que los enumeraran, y prácticamente ningún grupo de jóvenes de barrios populares pudo mencionar más de tres derechos (educación, trabajo y salud, nadie mencionó derecho de vida, lo cual nos muestra cómo los contextos de vida violenta parecen estar naturalizados). La excepción fueron algunos grupos de estudiantes de clase media-superior así como de un par de organizaciones civiles (son los casos de São Paulo y Medellín respectivamente).

Además, perciben el sistema de justicia como inequitativo e injusto, aseguran que éste da preferencia a clases económicas privilegiadas (o los políticos), lo que los lleva a un alejamiento y rechazo a la participación política y en algunos casos a un confuso rechazo de las normas. En tercer lugar, la mayoría de los jóvenes percibe una forma discriminatoria de aplicación de la ley en contra de ellos, por su forma de ser, de vestir y actuar.

Hay ciertas disonancias entre el conocimiento y el ejercicio (formal) de las normas, y de las prácticas legales. Hay un Habitus de respetar y usar la ley de manera casuística (valga la contradicción), personal, situacional. Los jóvenes reconocen que algunas normas son justas, algunas legítimas y otras aceptables; pero para la mayoría de ellos, pocas normas coinciden en estos tres aspectos. Conocerla, aceptarla y considerarla justa (o no), como legítima (o no), depende de su valoración y experiencias de vida cotidiana, que les muestra la brecha entre el valor ideal de las normas, la costumbre y la práctica recurrente.

En los ejercicios, la mayoría de los jóvenes distinguía entre normas sociales, costumbres sociales y la ley. Por ejemplo: los chismes, los conflictos por bajar la novia, por gritar, por el perreo, por agredirse verbalmente eran reconocidos como normas sociales. Pero así, mostraron que existe una conducta general de conflictividad interpersonal constante. Luego, el grafiti es considerado como aceptable y una forma de comunicación cotidiana permitida y legítima. En cambio, la piratería y la compra de las mercancías de moda es generalmente aceptada y considerada legítima (y hasta justa), no obstante que su origen sea desconocido o ilegal.

Su vida cotidiana les muestra la brecha entre la norma y la costumbre. Por un lado, varios grupos de jóvenes en todas las ciudades dijeron que algunas prácticas como 
7. El cinismo puede llegar a ser una concepción jurídica-formalista de las normas que absolutas, universales, y no permite entender cómo son aceptadas y socializadas. el robo, la portación de armas o el homicidio son ilegales, sin embargo, las califican en algunos casos de legítimas, principalmente si ellos tienen que llevarlas a cabo en determinadas situaciones. Algunos actúan voluntariamente en contra de las normas. Otros actúan en contra pero forzados por circunstancias locales, aceptando relaciones coercitivas, ilícitas, impuestas por grupos ilegales (varios de ellos armados) o por las propias autoridades que los coaccionan a comportamientos ilícitos e ilegítimos.

Otras prácticas, como la compra-venta de drogas ilegales producen ambivalencia, dado que si bien varios de ellos las aceptan y las consumen, otros más consideran que esta conducta genera tensiones y algunos las conocen como ilegales. No obstante el homicidio, generalmente, es rechazado y sólo en algunos casos lo aceptan como producto de la defensa personal.

Otra forma de entender esta manera de concebir y actuar la ley es el relativismo legal. Algunos estudios lo han definido como cinismo legal7, pero esta noción no abarca todas las situaciones que nos fueron presentadas, porque para determinar esta desafiliación legal es necesario considerar los contextos en los que las leyes son conocidas, percibidas y actuadas. En nuestro caso, consideramos que los jóvenes actúan con relativismo frente a la ley por dos razones: primero, porque las aplican casuísticamente y segundo porque adoptan, aceptan y practican las normas de diversos códigos éticos y legales sin que exista correspondencia con ellas. Además, ellos mencionan que es la propia autoridad la que impone la ley de manera inconsistente, arbitraria e injusta, por otro lado, dicha violación produce para ellos respuestas casuísticas a la aplicación de la ley.

Normas, concepción de la ley, la justicia y acceso a la justicia

A continuación describo algunos ejemplos de esta visión de las normas. Comenzaré con una descripción sucinta de algunas prácticas legales narradas por jóvenes en las distintas ciudades que consideramos emblemáticas de los problemas de conocimiento y aplicación de la ley, por parte de la autoridad y de percepción de legitimidad y justicia de la ley y de los actos de autoridad.

En primer lugar, destacaremos algunas respuestas comunes a los grupos focales de varias ciudades, para luego destacar algunos aspectos notables en cada grupo entrevistado en las ciudades.

Lo primero que se destaca en el estudio es el vago conocimiento que tienen los jóvenes de sus derechos. Muy pocos pueden mencionar cuáles son sus derechos y qué 
significa esto en su vida cotidiana. Sólo un grupo de jóvenes universitarios en Brasil y otro grupo de miembros de una asociación civil en Medellín lograron describir por completo sus derechos políticos, sus obligaciones y las de las autoridades.

El segundo tema que destaca es que existe una relación ambigua entre la legitimidad y la ilegalidad. Por ejemplo, en la ciudad de Cali prevalecen las actividades informales, en un ambiente donde la falta de oportunidades legítimas dentro de la sociedad no deja opciones. Los jóvenes viven en medio de esta relación ambigua de esta informalidad "cotidiana", omnipresente, en donde coexiste la ilegalidad.

En este contexto las instituciones formales y la escuela tienen un efecto limitado en los procesos de socialización de las leyes. Para algunas mujeres, todo viene desde el hogar, como... "también nos dejamos influenciar por las compañeras, amigos, la forma en que otros actúan, nos queremos parecer a los demás, aunque no se puede generalizar porque hay distintas personas".

Hay también una percepción de ser discriminados, "por qué me miran mal en la calle" ..."por qué la policía nos trata tan mal"..."por qué en los centros comerciales nos miranmal", entonces la respuesta es "para yo poder tener algo tengo que robar" (Concha-Eastman \& Concha, 2014: 284). La percepción de una discriminación doble, de la ley y de las autoridades por el hecho de ser jóvenes pobres.

Otro tema generalizado es el que mencionamos de la percepción arbitraria del comportamiento de las autoridades frente a la ley. A partir de este punto surgen varios comentarios vinculados con los contextos de vida de los jóvenes, que narraremos en cada ciudad.

\section{El caso de São Paulo, Brasil ${ }^{8}$}

Los grupos de adolescentes y jóvenes, que expresaron sus diferentes experiencias, hacen posible problematizar aspectos muy variados de la situación juvenil en un municipio de gran dimensión como lo es São Paulo. Con la excepción de un grupo de jóvenes entre 15 a 18 años, parte de los miembros de los otros tres grupos calificaron: la piratería, menores bebiendo y la prostitución, como conductas socialmente aceptables. En la sociedad brasileña, estos comportamientos son observables en la vida cotidiana: los productos pirata se comercializan de manera generalizada con la connivencia de los agentes de supervisión del comercio; la prostitución es una práctica consolidada en distintas áreas de las ciudades; y se venden bebidas alcohólicas a personas menores de 18 años de manera indiscriminada, aunque existe una legislación clara y muy divulgada con respecto a la ilegalidad de esta práctica y las sanciones pertinentes (Peres, 2014: 198).
8. Extracto de trabajo de Maria Fernanda Tourinho Peres, Maria de Lourdes Trassi Texeira, Marina Decot Sdoia y Roberta Tinoco Pinto Ferraz. 
9. Cf. Angélica Durán Martínez.

\section{El caso de Medellín, Colombia ${ }^{9}$}

Los jóvenes en Medellín, como ha señalado Pilar Riaño (2006), tienen percepciones y formas complejas de enfrentar la violencia. A pesar de la variedad de percepciones, existen ciertos patrones comunes. Para todos los jóvenes su experiencia de vida está marcada directamente por el conflicto, quienes no han perdido a un amigo o a un familiar en la violencia, han experimentado límites a su movilidad y han crecido viviendo y sintiendo la presencia de actores armados dentro de sus barrios. Estos jóvenes nombran y describen claramente a los grupos armados y criminales que disputan el control de la ciudad. Las y los jóvenes perciben el conflicto, el narcotráfico y la violencia como fenómenos poderosos (Durán, 2014: 321). Sin embargo, les resulta difícil cambiar algo de este contexto, o pensar que, a través de sus acciones, pueden mitigar el conflicto.

La discusión sobre la ley, la legalidad, los derechos, y la autoridad tomó formas diferentes en cada grupo, pero el común denominador fue la percepción de que la ley que se plasma formalmente no es la que se cumple, bien sea porque la justicia es inequitativa, o bien porque la ley en sí misma es injusta.

El concepto de cultura de legalidad surgió varias veces en una entrevista con un grupo de jóvenes de la Comuna 6, que son parte de una organización civil-barrial, que propone sacarlos de las bandas-combos, educarlos en una cultura de respeto de la ley y de prevención de la violencia. Una líder de esta organización señalaba que, si bien en el trabajo con muchos jóvenes y mujeres en situación de conflicto es difícil lograr que salgan de la delincuencia, ellos aspiran al menos a lograr que respeten la vida, "Lo que queremos es que al menos se genere una conciencia de que se respete la vida" (Durán, 2014: 370). La idea de legalidad como respeto a sí mismo y a otras personas emerge en los siguientes párrafos.

Para los jóvenes uno de los objetivos de su organización es rescatar a los jóvenes del conflicto y crear una cultura de legalidad. Sin embargo, sus respuestas reflejan una tensión entre lo que consideran legal y justo. Las respuestas tuvieron en común la idea de que la legalidad está más atada al respeto personal e interpersonal que al respeto por las leyes. En un caso una joven definió legalidad como el respeto por las normas que ellos internamente imponen para quienes forman parte de sus programas, por ejemplo, no consumir drogas dentro de las instalaciones de la organización. "Cuando el joven puede encontrar lo que él es, ahí es que se crea ese espacio de legalidad" (Durán, 2014: 371). Cuando empezamos a divisar la capacidad de hacer de los jóvenes, ahí se crea la legalidad." Varios de los jóvenes en este grupo estuvieron en la cárcel y enfatizaron que la cárcel no sirve para resocializar, y de ahí en parte viene su idea de que la legalidad va más allá de las leyes del Estado 
y su penalización, y en este sentido la legalidad se desliga de la institucionalidad: "A nosotros no nos gusta la cárcel, la cárcel degrada, usted en la cárcel de qué va a vivir, cualquier cosa puede pasar. Aquí la justicia es muy tensa." (Durán, 2014: 371).

Los jóvenes enfatizaron que quienes han tenido problemas con la ley o han estado en la cárcel tienen mucho potencial y son "ejemplos de vida", pero se ven limitados por sus antecedentes penales. Un joven varón definió la legalidad como el momento en el que un "joven puede encontrar lo que es" y otra mujer mencionó que la cultura de legalidad se crea a través del ejemplo. Es interesante notar que las mujeres parecieron enfatizar más la legalidad como una responsabilidad comunitaria, mientras que los hombres enfatizaron más la legalidad como la realización individual. Pero, en general, para hombres y mujeres la legalidad se concibe como un asunto de convivencia y respeto interpersonal, una realidad construida, más que como el respeto por las leyes (Durán, 2014: 372)

Los y las jóvenes criticaron el sistema educativo, afirman que éste tiende a coartar la libre expresión de los jóvenes, al prohibirles, por ejemplo, ciertas formas de vestir. En cuanto al trabajo, se enfatizó la precarización de las condiciones laborales, la falta de oportunidades y el que muchos jóvenes pueden ser estigmatizados por venir de las comunas violentas. Uno de los jóvenes señaló: "En este contexto al parecer es más necesario y primero ser un asesino, ser un criminal, tener sangre en nuestras manos para poder tener unas condiciones de vida mínimamente garantizadas, en términos del territorio, en términos de vivienda, educación de salud, incluso de nuestras construcciones individuales" (Durán, 2014: 373).

Este último comentario fue reproducido en todos los grupos al referirse a un programa de la Alcaldía de Medellín Ilamado 'Fuerza Joven', creado en 2009 con el fin de procurar retirar a algunos jóvenes que forman parte de 'combos' para que participen en capacitaciones y actividades, para lo cual se les otorga un subsidio mensual. Para todos los jóvenes entrevistados este programa era un fracaso, por un lado, por crear la idea de que delinquir paga y, por otro, porque los subsidios eran usados por los combos para comprar armas y financiarse, o porque los mismos combos extorsionaban a los jóvenes que recibían el subsidio.

Esas percepciones sobre derechos, justicia y legalidad sugieren que las intervenciones y programas de prevención que simplemente pretenden restablecer ideas de legalidad o convivencia en los jóvenes ignoran un problema de fondo y es que los jóvenes no pueden creer en la legalidad cuando perciben a la justicia, las instituciones y las leyes como inequitativas y corruptas. 


\section{Las experiencias de los jóvenes de Cali, Colombia ${ }^{10}$}

La percepción de lo legal o de lo ilegal en la muestra de los jóvenes que entrevistamos se da de manera vaga, como producto mismo de experiencias propias o ajenas, incluso, en ocasiones, sin reconocer que hay un acto delictivo en sus acciones. Por ejemplo, para un grupo entrevistado, lo ilegal..."Es todo lo que va contra la ley, por ejemplo, robar, lo que no está aprobado por la ley, hasta contra la ley de Dios". Pero luego comenta que: "Con este gobierno uno encuentra otra realidad, no nos ayuda sino que nos oprime. No se preocupan por la vida de nosotros. No ven las necesidades que hay en las casas. Entonces uno, como hombre de la casa, tiene que suplir las necesidades de la casa, y cómo lo hace: robando, matando y extorsionando" (Concha-Eastman y Concha, 2014: 295).

El tema del abuso sexual es percibido como algo completamente inaceptable. Todos los jóvenes de la muestra (con o sin pertenencia a bandas-combos o en conflicto con la ley) fueron enfáticos en rechazar la violencia sexual, especialmente la violación de niñas o niños. Lo interesante de abordar este tema es cómo las actitudes ante la justicia sobresalen al discutir este tipo de violencia.

Los participantes, especialmente los hombres jóvenes perciben a la policía como una institución falsa y corrupta, como el brazo duro de un Estado corrupto. La justicia está representada a través de las interacciones del sistema estatal con el que tienen más contacto: la policía.

\section{Los jóvenes y la ley en Guatemala ${ }^{11}$}

Los grupos focales integrados por jóvenes, hombres y mujeres, permitieron entender el conocimiento sobre la ley y las normas sociales, así como los temas considerados tabú para las y los jóvenes en una ciudad conocida por ser campo de batalla entre bandas de jóvenes criminales (la Mara 18 y la Mara Salvatrucha). El conocimiento de las y los jóvenes sobre las leyes y sus derechos es mínimo, la mayoría mencionaron que desconocen los programas para los jóvenes, sus derechos y cómo actuar ante alguna situación con la policía. Un ejemplo son las revisiones en la calle hechas por los policías. Los jóvenes no las ubicaron como una falta a sus derechos humanos. Algunos temas como drogarse, el aborto, el acoso, el grafiti, entre otros, están permeados por las normas y los valores socialmente establecidos (Urusquieta, 2014: 450).

Lo jóvenes ubican como acciones legales algunas actividades culturales como el baile. Pero el "perreo" es considerado por las mujeres como machista y denigrante para ellas, mientras que para los hombres es aceptable; aun así ellos reconocen un lenguaje sexista en sus mensajes. 
El grafiti, por otra parte, comienza a ser socialmente aceptado entre los jóvenes. Es un elemento central de su expresión cultural, a diferencia de las "placas", señalamientos en las calles que indican o delimitan un territorio entre pandillas, que son vistas como algo no aceptable.

El acceso a armas y el permiso para portarlas es un tema importante por el alto índice de homicidios cometidos por arma de fuego, pero también ocurre que los guardias privados y los ciudadanos utilizan armas como un mecanismo de defensa ante el alto índice de robos y extorsiones. Para los jóvenes entrevistados portar arma es aceptable siempre y cuando se tenga permiso para utilizarla, lo que nos muestra, por un lado, el alto grado de sensación de inseguridad, y por otro, la facilidad que existe para conseguir armas (Urusquieta, 2014: 451).

El consumo de drogas es un tema de mucha controversia entre las y los jóvenes. Es interesante notar que un gran número de entrevistados definieron como drogas: el alcohol, el tabaco y los tranquilizantes. La mayoría coincidió que hay drogas que no son ilegales y que son de mayor consumo, también dijeron que el alcohol y la mariguana son consumidos regularmente entre las y los jóvenes.

Por otra parte, el aborto es otro tema de gran controversia entre las y los jóvenes, no está legalizado y tiene penas tipificadas en la ley. No obstante, un fenómeno oculto es el número de abortos practicados de forma clandestina ${ }^{12}$. La percepción de las y los jóvenes es que el aborto no es aceptable, sólo en los casos de violación (Urusquieta, 2014: 451).

A diferencia de otras ciudades del sub-continente, entre los jóvenes guatemaltecos la religión fue expresada con claridad, porque para ellos juega un papel importante en sus valoraciones legales. Existe un alto número de jóvenes que practican alguna (88\%), donde la religión católica y la evangélica son las predominantes. En ese sentido existe una especie de "doble moral" en el discurso de las y los jóvenes, porque cuando hablamos de aborto la mayoría se expresó en contra porque contradice sus creencias religiosas y morales. También, en otro sentido, en entrevistas realizadas a algunos ex pandilleros, ellos mostraban profesar alguna religión, incluso algunos hablaban de "dar gracias a Dios" al realizar sin problemas alguna acción ilícita (Urusquieta, 2014: 452)

Como podemos apreciar en esta distribución de respuestas, los jóvenes entrevistados en Guatemala presentan un visión de las normas que muestra algunas disonancias con la ley. Un tema importante es portar armas; otro tema notorio es robar. Si bien lo clasifican como ilegal e inaceptable, actúan en contra de sus propias declara-
12. $24 \%$ de las mujeres, que genera que exista una alta tasa de mortalidad materna por esta causa. 
FIGURA 1

CLASIFICACIÓN DE CONCEPTOS LEGAL-ILEGAL

EN LAS ENTREVISTAS A JÓVENES EN GUATEMALA

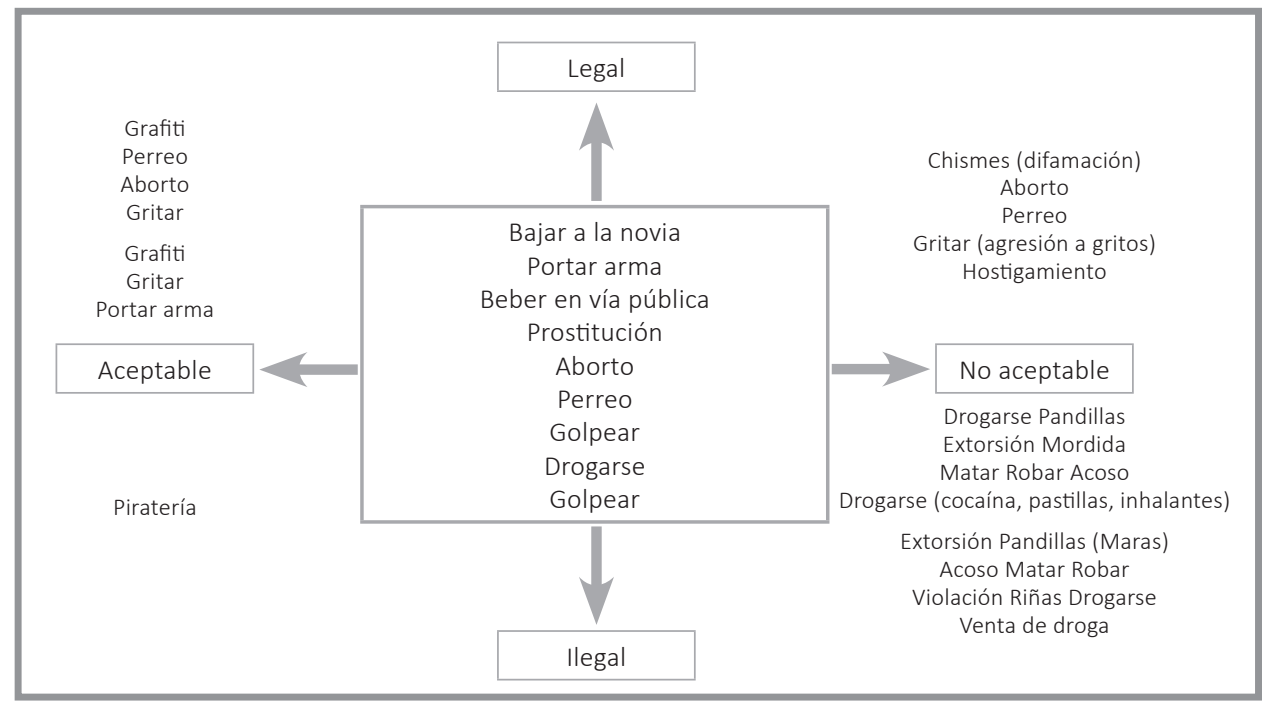

Fuente: Elaboración del autor.

ciones (como lo hicimos notar en el texto). Finalmente, hay un área de controversias muy grande (al centro) entre diversas normas sociales y legales.

La brecha entre legalidad e ilegalidad es muy corta en algunas acciones, algunos jóvenes viven y perciben algunas acciones ilegales como parte de su cotidiano, y quienes han cometido acciones ilícitas lo ven como un proceso normal en su vida:

Antes salía a robar también. Primero me invitaron, fuimos una noche, íbamos con una 38 de verdad y un maje que era seguridad cargaba ese mazo y era de la empresa de él y fuimos caminando hasta La Kennedy, La San Jorge, la iglesia mormona y el maje se huequeaba (me daba miedo) o no se atrevía a poner el mazo, llegamos hasta La Alameda sin nada, estábamos parando taxis...Imagina, no nos paraban los taxis porque igual nos presentían, cuando regresamos le pedí el mazo al maje, llevaba mi gorro y lo metí ahí, se lo di a otro cuate, (...) y cuando el maje se fue como que nos armamos de huevos (...) le pusimos a una ruca, de mala suerte sólo le quitamos fichas, un teléfono que estaba bloqueado, ese día sólo hueveamos tres teléfonos, dos memorias y dinero (Urusquieta, 2014: 453).

Para los jóvenes, el asalto a transeúntes es una actividad que en algún momento realizan para obtener algo de dinero. Entre ellos no es visto de manera negativa sino como parte de la inmediatez de su contexto. 
Desde hace algunos años, Argentina, como el resto de los países de América Latina, ha registrado un incremento del delito y de la preocupación por la seguridad. Una de las consecuencias de ese proceso es la amplificación del proceso de "presunción generalizada de peligrosidad" (Kessler, 2009, 2011; Lianos \& Douglas, 2000), que es la tendencia a evaluar el mundo a través de categorías de amenaza de diverso tipo. El punto que nos interesa es que, tal como advierten estos autores, en el marco de una sociedad democrática consolidada, la amenaza se convierte en un criterio legítimo para evitar al otro; para impedir que se acerque y, si es posible, mantenerlo lo más alejado posible. Esta alteridad amenazante se instituye como un criterio de separación legítimo. En este caso encarnada en ciertos jóvenes o grupos de ellos y en ciertos barrios (Kessler, 2008). Así el marco de la ley y de la institucionalidad democrática sólo puede legitimarse si ese otro es percibido como peligroso.

Es interesante remarcar la conciencia de la discriminación que aparece en los grupos de jóvenes. Según los autores, están operando en tal conciencia dos procesos superpuestos. Por un lado, una creciente sensibilidad frente a todas las formas de discriminación y una mayor aceptación de la diversidad vinculada a los avances que Argentina ha conocido en los últimos años en materia legislativa y en la opinión pública. Junto a esto, y en sentido opuesto, la preocupación por la seguridad ha amplificado el proceso de "empeligrosamiento", es decir, evaluar el mundo a través de categorías de amenaza de diverso tipo. De este modo la adopción de estrategias de evitamiento de ciertos individuos o grupos sólo puede legitimarse si éstos son ubicados como peligrosos. El propio autor cita un estudio en cuatro ciudades del Mercosur-Buenos Aires, Río de Janeiro, Asunción y Montevideo- que muestra que la percepción de discriminación era mayor en la capital argentina (PNUD, 2009). Es posible que en Buenos Aires opere a la vez la presunción de peligrosidad junto a una fuerte sensibilidad contra la discriminación debido a la fortaleza relativa de los legados históricos de igualdad y los más novedosos avances en el respeto de los derechos humanos.

Los tipos de interacción entre los jóvenes y las autoridades determinan buena parte de la construcción de la percepción de la ley, la legitimidad y el orden. El contacto más frecuente que establecen los jóvenes de sectores populares con la policía ocurre en las calles. La práctica de parar y revisar es un tipo de interacción que se ubica dentro de lo que algunos autores (Reisig \& Parks, 2002; Hinds, 2008) han denominado "encuentros formales" en tanto se producen como parte de la labor institucional de la policía. Otros ejemplos de este tipo son las reuniones barriales, en actividades conjuntas y visitas de la policía a las escuelas (Kessler, 2014: 100). 


\section{Los casos de México}

14. Con algunas excepciones individuales, las entrevistas colectivas a los jóvenes en conflicto con la ley fueron facilitadas y mediadas por las autoridades de administración de justicia de las ciudades estudiadas.
En este país realizamos el estudio en cinco ciudades. A continuación presento una síntesis de algunos elementos centrales de las entrevistas en Ciudad Juárez, León y Ciudad de México ${ }^{14}$. Los conceptos de legalidad fueron explorados a través de dinámicas en las que los participantes eran invitados a clasificar ciertas conductas como legales o ilegales, o aceptables y no aceptables. Este ejercicio reveló las profundas paradojas que existen en la definición de lo que es legal e ilegal, en tanto muchos comportamientos que se reconocen como prohibidos por la ley se perciben como aceptados, tolerados y facilitados por las autoridades, o como conductas muy comunes. Esta tensión creó una dinámica muy interesante en los grupos de mujeres y hombres estudiantes, así como en aquellos con conflictos con la ley. La gran mayoría clasificaron como legales comportamientos que reconocen como prohibidos por la ley, pero que son tolerados por la autoridad. Así, manifiestan esta situación casuística en la cual el ejemplo de la autoridad determina la percepción de la norma como legal, y no una asociación abstracta a una norma genérica.

Por ejemplo, en Ciudad Juárez, al preguntar si la venta de drogas era legal o ilegal, la respuesta inmediata fue "legal". Unos segundos después, algunas mujeres dijeron: "Pues no es legal pero... pues sí lo permiten". Esta discusión frente al tema de lo qué es legal o ilegal sugiere que la percepción de ilegalidad e injusticia está marcada por la tolerancia y la impunidad que permiten las autoridades en estos actos. Esta tolerancia parece cambiar totalmente la noción de legalidad, y ante la inacción de las autoridades lo ilegal se torna en legal. Por ejemplo, al preguntar si el acoso era legal o ilegal surgió un debate, pues al principio las jóvenes dijeron que por ser algo frecuente, era legal. Sin embargo, otras respondieron que era ilegal en tanto ante el acoso sí había respuesta de las autoridades (Alanís \& Durán, 2014: 102).

Respecto a las pandillas se mencionó que su legalidad dependía de si hacían daño o no, y aquí salió el tema de las pandillas más grandes, articuladas al crimen organizado, como los Aztecas, que se describieron como un fenómeno inaceptable, pero al preguntarles si era legal o no, una vez más surgió la tensión y una de las participantes interpeló: "Estamos haciendo ver como que es aceptado por nosotros, ya lo vemos normal, como que esto pasa, pero debimos haber estado siempre en desacuerdo", a lo que otra respondió: "Es que estamos en desacuerdo, pero está pasando", y otra joven interpeló de nuevo: "Si estás en desacuerdo quiere decir que está pasando, pero no lo apruebas" (Alanís \& Durán, 2014: 103).

Esta variedad de formas de percibir distintas conductas revela que no existe un único estándar entre los jóvenes para juzgar y entender las conductas, su legalidad, o aceptabilidad. Sin embargo, sí sugieren que una noción de legalidad que simple- 
mente se reduce al apego a las normas no refleja lo que las y los jóvenes sienten frente al sistema de justicia.

\section{Los jóvenes en la Ciudad de México}

En este caso mostramos los ejercicios realizados dividiendo los grupos de hombres y mujeres adolescentes en conflicto con la ley. Esto nos permite distinguir los patrones de aceptación de las leyes por jóvenes que se encuentran en alguna forma de tratamiento legal. Además reúnen una serie de características particulares sobre el resto del conjunto. La mayoría presenta rezago, abandono escolar y una baja socialización en las leyes. Una historia familiar de abandono, violencia o de involucramiento de los padres o tutores en actividades ilícitas; en algunos casos la "educación delictiva" ocurrió entre los familiares, padres, tíos o hermanos. Entre ellos el conocimiento de normas, valores y derechos que es muy escaso. Por ejemplo, no presentan claridad respecto al concepto de derechos como persona. Sí tienen en cambio cierta idea de titularidad (desert) en cuanto a sus aspiraciones de consumo, como algo que merecen y que para acceder a estos bienes de consumo (de moda) es legítimo actuar en contra de la ley. Además fue notorio en este grupo una menor capacidad de argumentar sobre las respuestas a los términos enunciados y, además, es entre el grupo de jóvenes varones que puede mostrarse una mejor ubicación de sus respuestas en un marco de cinismo legal. A diferencia de los grupos descritos en

\section{TABLA 4}

EJERCICIOS DE CLASIFICACIÓN DE CONCEPTOS CONSIDERADOS COMO LEGALES, ILEGALES Y DISENSOS ENTRE ADOLESCENTES EN EL D.F.

\begin{tabular}{|c|c|c|c|c|}
\hline \multirow{2}{*}{ Clasificación } & \multicolumn{2}{|c|}{ Grupo focal jóvenes sin conflicto } & \multicolumn{2}{|c|}{ Grupo focal jóvenes con conflicto } \\
\hline & Mujeres & Hombres & Mujeres & Hombres \\
\hline Legal & $\begin{array}{l}\text { Grafiti, chismes, } \\
\text { pandillas, beber en vía } \\
\text { pública, "perreo", bajar } \\
\text { a la novi@, aborto, } \\
\text { gritar, hostigamiento, } \\
\text { portar arma. }\end{array}$ & $\begin{array}{l}\text { Grafiti, golpear, pan- } \\
\text { dillas, "perreo", gritar, } \\
\text { aborto, chismes. }\end{array}$ & $\begin{array}{l}\text { Aborto, riñas, gritar, } \\
\text { extorsión. }\end{array}$ & Gritar. \\
\hline llegal & $\begin{array}{l}\text { Piratería, mordida, } \\
\text { extorsión, acoso, matar, } \\
\text { robar, violación, "mo- } \\
\text { near" banda armada, } \\
\text { venta de droga, riñas. }\end{array}$ & $\begin{array}{l}\text { Piratería, drogarse, } \\
\text { extorsión, mordida, } \\
\text { acoso, robar, matar, } \\
\text { violación, banda } \\
\text { armada, "monear", } \\
\text { venta de droga } \\
\text { hostigamiento. }\end{array}$ & $\begin{array}{l}\text { Violación, acoso, homi- } \\
\text { cidio, grafiti, golpear, } \\
\text { robar, portar armas, } \\
\text { mordida. }\end{array}$ & $\begin{array}{l}\text { "Monear", pandillas, } \\
\text { chismes, riñas, robar, } \\
\text { venta de droga, } \\
\text { extorsión, bandas } \\
\text { armadas, drogarse, } \\
\text { matar, violación, acoso, } \\
\text { piratería, beber en } \\
\text { vía pública, mordida, } \\
\text { hostigamiento. }\end{array}$ \\
\hline Disensos & $\begin{array}{l}\text { Prostitución, drogarse, } \\
\text { golpear. }\end{array}$ & $\begin{array}{l}\text { Bajar a la novi@, portar } \\
\text { arma, beber en vía } \\
\text { pública, prostitución, } \\
\text { riñas. }\end{array}$ & $\begin{array}{l}\text { Hostigamiento, } \\
\text { prostitución, venta } \\
\text { de drogas, drogarse, } \\
\text { pandillas. }\end{array}$ & $\begin{array}{l}\text { Aborto, grafiti, golpear, } \\
\text { "perreo", portar arma, } \\
\text { bajar a la novi@. }\end{array}$ \\
\hline
\end{tabular}


TABLA 5

EJERCICIO DE CLASIFICACIÓN DE CONCEPTOS

ACEPTABLES, NO ACEPTABLES Y DISENSOS ENTRE ADOLESCENTES EN EL D.F.

\begin{tabular}{|c|c|c|c|c|}
\hline \multirow{2}{*}{ Clasificación } & \multicolumn{2}{|c|}{ Grupo focal jóvenes sin conflicto } & \multicolumn{2}{|c|}{ Grupo focal jóvenes con conflicto } \\
\hline & Mujeres & Hombres & Mujeres & Hombres \\
\hline Aceptables & $\begin{array}{l}\text { Grafiti, chismes, } \\
\text { pandillas, beber en vía } \\
\text { pública, perreo, bajar a } \\
\text { la novi@, portar arma, } \\
\text { piratería, mordida. }\end{array}$ & $\begin{array}{l}\text { Piratería, grafiti, } \\
\text { golpear, pandillas, } \\
\text { "perreo", gritar }\end{array}$ & $\begin{array}{l}\text { Portar arma, golpear, } \\
\text { gritar, bajar a la novi@, } \\
\text { "monear", drogarse }\end{array}$ & $\begin{array}{l}\text { Piratería, grafiti, bandas } \\
\text { armadas, drogarse }\end{array}$ \\
\hline No aceptables & $\begin{array}{l}\text { Aborto, gritar, hosti- } \\
\text { gamiento, extorsión, } \\
\text { acoso, matar, robar, } \\
\text { violación, riñas, banda } \\
\text { armada, venta de } \\
\text { droga, "monear". }\end{array}$ & $\begin{array}{l}\text { Aborto, chismes, } \\
\text { drogarse, extorsión, } \\
\text { mordida, acoso, robar, } \\
\text { matar, banda armada, } \\
\text { violación, "monear", } \\
\text { venta de droga, hosti- } \\
\text { gamiento }\end{array}$ & Hostigamiento, chismes & $\begin{array}{l}\text { Acoso, chismes, } \\
\text { hostigamiento, riñas, } \\
\text { violación, "monear" }\end{array}$ \\
\hline Disensos & $\begin{array}{l}\text { Prostitución, drogarse, } \\
\text { golpear. }\end{array}$ & $\begin{array}{l}\text { Bajar a la novi@, portar } \\
\text { arma, beber en vía } \\
\text { pública, prostitución, } \\
\text { riñas }\end{array}$ & $\begin{array}{l}\text { Matar, aborto, robar, } \\
\text { bandas armadas, riñas, } \\
\text { piratería, extorsión, } \\
\text { prostitución, "perreo", } \\
\text { beber en vía pública }\end{array}$ & $\begin{array}{l}\text { Robar, gritar, venta } \\
\text { de drogas, bajar a la } \\
\text { novi@, prostitución, } \\
\text { mordida, extorsión, } \\
\text { "perreo", matar, portar } \\
\text { arma, aborto, golpear }\end{array}$ \\
\hline
\end{tabular}

Fuente: Elaboración en base a los datos de los grupos focales del Distrito Federal.

otras ciudades, en este caso no hay una clara mención de la influencia 'coercitiva' del medio, del contexto donde viven.

\section{Discusión}

El presente trabajo intenta mostrar algunos aspectos centrales en la relación entre los jóvenes de barrios populares de América Latina y los procesos de socialización de las leyes. En el mismo hemos procurado hacer énfasis en cómo los jóvenes perciben, conocen y actúan hipotéticamente frente a la ley, y a algunos problemas de conocimiento abstracto, y de aplicación práctica de las leyes que hemos tratado de ubicar en la literatura. Ejemplificamos de manera simple algunas narrativas de entrevistas realizadas con jóvenes en diversas ciudades de la región. Un aspecto a destacar está vinculado con el concepto de socialización legal acuñado por la literatura especializada. Diversos estudios se han propuesto analizar de qué modo las primeras experiencias con instituciones ligadas a la ley -entre las que la policía ocupa un lugar de centralidad-configurarán los comportamientos y percepciones posteriores con respecto a la propia ley. De este modo, experiencias positivas (que pueden ser tanto personales como a través de los grupos de pares o el entorno) derivarán en actitudes y percepciones de aceptación y colaboración con las instituciones legales mientras que experiencias negativas conducirán a una menor colaboración y conformidad. En esta sección se mencionan los problemas de cinismo legal, desafiliación o varias formas de disonancia entre el conocimiento y la 
observancia práctica de las leyes. En el caso de los jóvenes entrevistados, en línea con los resultados de investigaciones de otros países, se advierte efectivamente un proceso de erosión de la socialización legal en tanto se observa un deterioro de la legitimidad de las interacciones de la institución policial contra los jóvenes que está narrada como conflicto violatorio de derechos. Esta falta de legitimidad se vincula con la evaluación negativa de la justicia de procedimiento; la sensación de que la policía se maneja con profiling y sin justicia en su accionar, así como la percepción de su inoperancia.

Sin embargo, en este punto habría que hacer alguna aclaración con respecto a la perspectiva teórica de la socialización legal. En el caso de los jóvenes entrevistados para este estudio, y en el de gran parte de los jóvenes de sectores populares, ese deterioro de la imagen de la policía como institución legítima no conduce necesariamente, como podría desprenderse de algunos de estos estudios, a una situación de cinismo legal ni, menos aún, de retraimiento moral (moral disengagement). Si bien esta situación puede darse en ciertos grupos más consolidados y volcados a conductas delictivas, en el caso de otros jóvenes que no se encuentran en conflicto con la ley, esa falta de legitimidad no redunda en un cuestionamiento generalizado de la ley en sentido amplio ni en la conformación de conductas contrarias a las reglas. Muchas veces su crítica al accionar policial se apoya justamente en un conocimiento (y reconocimiento) de las leyes; leyes en las que ellos creen pero consideran que los policías no respetan.

La literatura acuña el concepto de "socialización legal" para dar cuenta de la internalización de normas formales e informales, respeto a la ley y a la autoridad policial. También algunos autores encontraban que en principio la socialización legal estaba muy extendida en edades tempranas y que justamente la mala relación con la policía, la falta de percepción de justicia de procedimiento y/o justicia distributiva en su accionar, erosionaba tal socialización legal. Quisiéramos remarcar dos puntos al respecto. En primer lugar, todo parece abonar la hipótesis de una erosión de la socialización legal por malas experiencias de contacto con las autoridades, en especial la policía. Pero también nos parece que la idea de socialización legal hace reposar demasiado peso para la internalización de la ley y sobre todo en la acción policial.

Resumen: Varios países de América Latina se han visto involucrados en una guerra muy violenta contra las drogas, las pandillas y el crimen organizado. Los gobiernos y las élites latinoamericanas han implementado una serie de reformas institucionales cuestionables a la justicia y los sistemas jurídicos en su intento de no promulgar esta "guerra". Esta aplicación ha sido corroída por la incapacidad de las mismas élites de realizar y respetar estas normas, ya que existe una fuerte corrupción y la impunidad entre ellos. Su comportamiento tiene un fuerte impacto en las expectativas de los ciudadanos, en su percepción de la impunidad, la corrupción y los valores de la democracia y el Estado de Derecho. En medio de estas batallas, la población juvenil ha sido blanco de ataques o culpado por los principales delitos que se haya cometido efectivamente por los diferentes acto- 
res armados legales. Una cuestión es la creciente participación de los jóvenes en asumido estas actividades ilegales. Otra cuestión es la de menores su socialización en las normas jurídicas, su consentimiento y reconocimiento.

Palabras clave: Jóvenes, percepción, justicia, leyes y policía.

Abstract: Several countries of Latin American have been engaged in an extremely violent war against drugs, against gangs and organized crime. Latin American governments and elites have implemented a series of questionable institutional reforms to the justice and legal systems in their failing attempt to enact this "war". This implementation has been corroded by the inability of the same elites to perform and respect these regulations, because there is strong corruption and impunity among them. Their behavior has strong impact in the expectations of citizens, in their perception of impunity, corruption and values about democracy and the rule of law. In the middle of these battles, youth population has been targeted or blamed for major crimes that are actually committed by different armed legal actors. One issue is the assumed increasing involvement of youth in these illegal activities. Another issue is the juvenile their socialization on legal norms, their consent and recognition.

Keywords: Young people, perception, justice, laws and police.

\section{Referencias}

ALVARADO, Arturo Mendoza (Coord.). Violencia juvenil y acceso a la justicia en América Latina. México, D.F.: El Colegio de México; Centro de Estudios Sociológicos, 2014.

BANDURA, Albert. Selective activation and disengagement of moral control. Journal of Social Issues, v. 46, n. 1, p. 27-46, 1990.

FAGAN, J.; TYLER, T. Policing, order maintenance and legitimacy. In: MESKO, Gorazd; PAGON, Milan; DOBOVSEK, Bojan (Eds.). Policing in Central and Eastern Europe: dilemmas of contemporary criminal justice, faculty of criminal justice. Slovenia: University of Maribor, 2004.

HINDS, L. Building police-youth relationships: the importance of procedural justice. The National Association for Youth Justice, v. 7, p. 19-33. Los Angeles; London; New Delhi; Singapore: Sage Publications, 2007.

HIRSCHI, T. Causes of delinquency. Berkeley, CA: University of California Press, 1969.

HYMAN, Herbert. Political socialization. New York: Free Press, 1959.

KESSLER, Gabriel. Inseguridad subjetiva: un nuevo campo de investigación y políticas públicas. Estado, democracia y seguridad ciudadana, p.107-142, Pnud, 2008.

El sentimiento de inseguridad. Sociología del temor al delito. Argentina: Siglo XXI, 2009. 
- La extensión del sentimiento de inseguridad en América Latina relatos, acciones y políticas en el caso argentino. Revista Sociologia e Política, v. 19, n. 40, p. 83-97, 2011.

LIANOS, Michalis; DOUGLAS, Mary. Dangerization at the end of deviance: the institutional environment. In: GARLAND, D.; SPARKS, R. (Eds.). Criminology and Social Theory. British Journal of Criminology, v. 40, p. 261-278. Oxford: Oxford University Press, 2000.

PROGRAMA DE NACIONES UNIDAS PARA EL DESARROLLO. Informe sobre el desarrollo humano. Guatemala: PNUD, 2009.

REISIG, Michael D.; PARKS, Roger B. Satisfaction with police. What matters? Washington, D.C.: Departament of Justice; Office of Justice Programs; Nacional Institute of Justice, 2002.

REISS, Albert. The police and the public. The Journal of Criminal Law, Criminology and Police Science, v. 63, n. 3, p. 409-411, 1972.

RIAÑO, Pilar. Jóvenes, memoria y violencia en Medellín: una antropología del recuerdo y el olvido. Medellín: Universidad de Antioquia, 2006.

SAMPSON, Robert; BARTUSCH, Dawn. Legal cynicism and (subcultural?) tolerance of deviance: the neighborhood context of racial differences. Law and Society Review, n. 32, p. 777-804, 1998.

SIMON AND SHUSTER INTERNATIONAL DICTIONARY.

SYKES, Gresham M'Cready; MATZA, David. Técnicas de neutralización: una teoría de la delincuencia. Caderno CRH, v. 21, n. 52, p. 163-170, El Salvador, Ene./Abr. 2008.

TAPP, June; LEVIN, Felice. Law, justice and the individual in society: psychological and legal issues. USA: Harcourt School, 1977.

TYLER, T. Trust and law abidingness: a proactive model of social regulation. Boston University Review, n. 81, p. 361-406, 2001.

TYLER, Tom; YUEN, Huo. Trust in the law: encouraging public cooperation with the police and courts. Russell-Sage Foundation, v. 82, n. 2, p. 248, New York, 2002.

ZAVALETA, José Alfredo; KESSLER, Gabriel. ALVARADO, Arturo; ZAVERUCHA, Jorge. Las representaciones e interacciones y policías y jóvenes. En prensa, 2015. 